\title{
Paste thickeners in India's iron and steel industry
}

\author{
JL Johnson WesTech Engineering, LLC, USA \\ BP Misra WesTech Process Equipment India Pvt Ltd, India
}

\begin{abstract}
Iron production in India has seen rapid growth over the last few years, significantly exceeding forecasts. This growth has accentuated several issues regarding management of the slimes, dewatering, and tailings storage facilities (TSF). The number of slime pelletising beneficiation plants has increased to produce pellets for domestic use and exports. Pellet plants vary in size from 1 to more than 8 Mtpa pellet production. Slime beneficiation can produce tailings with more than $90 \%$ passing 20 microns $(\mu \mathrm{m})$. In light of recent world iron tailings disasters, there has been a focus on much lower risk tailings storage systems. Plants have significant obstacles to overcome in the management of these slime tailings; the tailings' very fine particle size distribution (PSD) is notorious for poor filtration rates, small TSF areas are available, stream variability can greatly affect dewatering efficiency, and water management at the TSF in high rainfall, to name a few. Paste thickener technology, which provides solutions to several of these challenges, has entered the Indian iron market. The first installation was in 2015 at Shri Bajrang Power and Ispat Ltd Tilda pellet plant. This paper features additional Indian paste thickener sites, discussing dewatering variable feed streams, thickener operation and results, and methods of TSF management.
\end{abstract}

Keywords: paste thickeners, surface stack, Iron slimes

\section{Introduction}

India has a robust iron and steel industry, with growth reported by the India Bureau of Mines (2020a, b) as "exponential". Earlier iron production forecasts needed to be almost doubled to predict the actual 2019-2020 production. Growth in all areas of iron production (lumps, sinter, and pellets) is being encouraged by the government. Of particular interest for this paper is the growth in beneficiation plants producing tailings and the handling of iron slimes. The product from the slimes fraction $(-150 \mu \mathrm{m})$ is used in producing pellets. The pellet plants are often located at ports (sometimes $250 \mathrm{~km}$ from the beneficiation plant). The slimes products are pumped to the pelletising plants. The strength of the pellets themselves makes them ideal for transport to, and for use in, steel-making furnaces. The export of pellets has grown from just under 1 to over 12 Mtpa since 2015. Pelletising plants' capacity has not been reached, with currently about $70 \%$ usage. There is room for more growth. The beneficiating plants discharge slimes tails that can contain high iron (more than $50 \% \mathrm{Fe}$ ) and very fine particle size distribution (PSD), with as much as $100 \%$ passing $20 \mu \mathrm{m}$. These slimes bring with them process issues that range from dewatering to storage complications.

\section{Dewatering fine PSD}

The beneficiating plants employ sizing, grinding, magnetic, and gravity concentration methods. The beneficiation steps will vary from site to site based on ore character and target products. Characteristically, Indian iron ores are fragile in nature, and mining and processing combined generate substantial amounts of fines and slimes (20-25\% of the feed). The production of slimes tailings does appear to be universal. The nature of the concentration processes and the feed variability result in a wide range of PSD in the tailings on an hourly basis. Examples of daily analysis of the PSD from two plants are presented in Table 1. The PSD was determined from grab samples representing one to three shifts in the day for a period of about a month. The spread of percent passing in each size fraction is almost identical. These very fine streams are sent to be dewatered in preparation for storage. With the recent iron TSF failures around the world, low-risk TSF storage methods are sought. The main dewatering technologies considered are those that minimise or eliminate free 
water at the TSF; namely, paste-type thickeners and filters. The fine nature and the variability of the PSD can have significant effects on dewatering.

Table 1 Particle size distribution - Indian slimes

\begin{tabular}{llclc}
\hline Passing, micron & \multicolumn{2}{l}{ Plant 1 - min and max } & \multicolumn{2}{c}{ Plant 2 - min and max } \\
\hline $45 \mu \mathrm{m}$ & 80 & 99 & 83 & 99 \\
$32 \mu \mathrm{m}$ & 78 & 97 & 81 & 98 \\
$20 \mu \mathrm{m}$ & 74 & 93 & 76 & 93 \\
$10 \mu \mathrm{m}$ & 62 & 82 & 65 & 83 \\
\hline
\end{tabular}

For the filter, the finer fraction of these slimes will dictate the performance as seen in the filtration rate and cake moisture (Palmer 2020; Vilela \& Salvate 2020). Palmer provides an example of a study comparing filtration of the cyclone feed to the cyclone products. For the sample studied, the cyclone overflow collected about $30 \%$ of the total feed weight. The filtration rate measured for the overflow slurry was about $30 \%$ of that determined for the cyclone feed, 1,000 and $3,200 \mathrm{~kg} / \mathrm{m}^{2} / \mathrm{h}$, respectively. With the filtration rate around $30 \%$ of the rate measured for the feed and the overflow dry tonnes per hour (tph) also approximately $30 \%$ of the feed, the resulting filter required for either stream would be similar in size. This illustrates how filter performance is affected by PSD variation. Periodically reducing the filtration rate due to PSD swings will create a bottleneck at the filter. When a filter is faced with wide variable feed streams, the capacity or cycle time will vary in spite of the plant production. Palmer explains that the fine particles, clays, and oxidised material will dominate the filterability of the stream and should be used as the basis for any design or modelling.

The Vilela \& Salvate discussion addresses slow filtering fines with higher pressure filtration. The paper provides test results for three different samples. The PSDs for these sites are generally coarser than the iron slimes experienced in India. The effect of PSD swings can be very traumatic for installed filters. If the fines fraction increases beyond what is planned for the installed filter, then capacity will be adversely affected.

For paste-type thickeners, the finer particles will affect the flocculant consumption and the weight percent $(\% \mathrm{~m})$ solids produced. The ArcelorMittal Nippon Steel (AMNS) Kirandul plant currently is using two-stage thickening with a high-rate thickener at the plant. Thickener underflow is then fed to the paste-type thickener. The high-rate thickener is producing an underflow averaged at $35 \% \mathrm{~m}$ solids. This underflow is then dewatered to $49-59 \% \mathrm{~m}$ solids in the paste thickener. This wide underflow range is due primarily to changes in the stream, like the PSD variation. The underflow, however, had a consistent yield stress, the magnitude depending on the operating conditions.

During February 2021, an optimisation study was conducted at the Kirandul paste thickener. The paste thickener was operated for 10 days while the feed conditions and thickener operating conditions were tracked. After the environment in which the thickener needed to operate was identified, thickener operating conditions were optimised (flocculant, bed level, underflow discharge rate, etc). The operating environment can be described with the following statements:

- The thickener feed varied greatly from the average 85 tph with swings of plus or minus 60 tph.

- The feed was interrupted for hours at a time.

- The feed PSD varies as shown in Table 1.

- The underflow discharge rate was operated independent of the thickener conditions but varied greatly.

- Flocculant addition was manually controlled and was difficult to operate for these feed conditions. 
The thickener produced a steady underflow yield stress even during this difficult operating environment (Figure 1). Note that the PSD became finer after 5 February, contributing to the \%m solids decrease $(59-55 \% \mathrm{~m})$, but the yield stress remained relatively steady in the upper $50 \mathrm{~s}$. This illustrates the point that a paste thickener is designed and operated to produce a yield stress, not an underflow density.

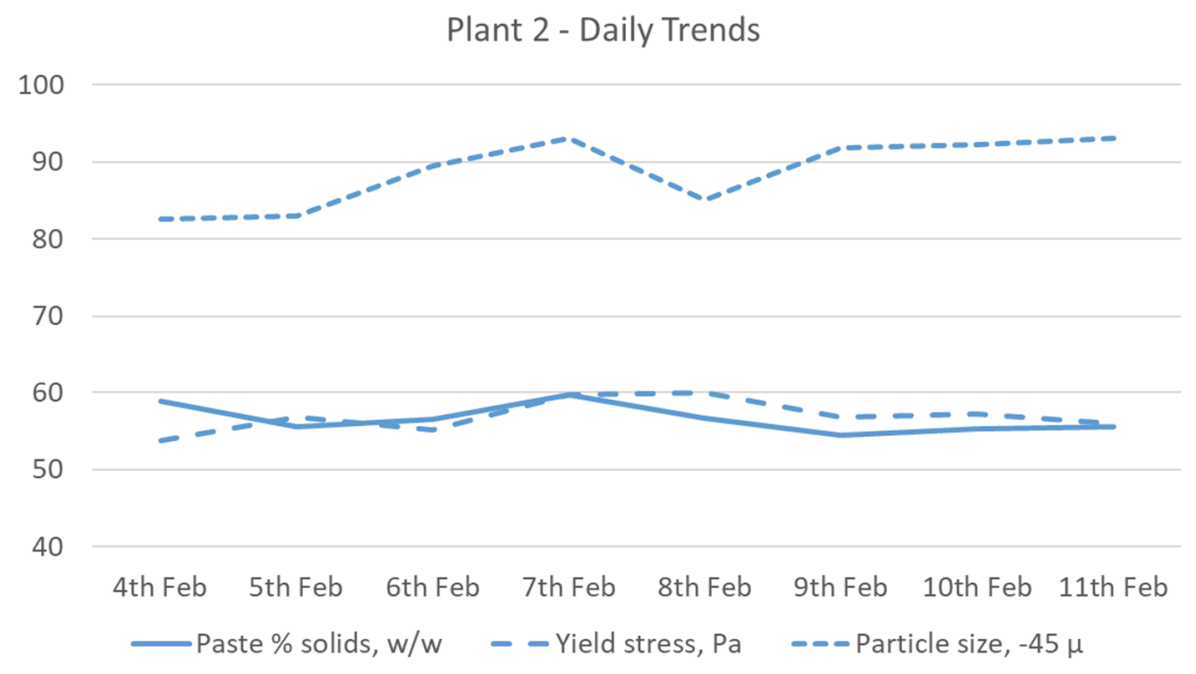

Figure 1 Comparison of PSD and the underflow performance (\%m and yield stress)

The optimisation study recommended that the target bed level be higher to more effectively handle the swings in dry tph to maintain a minimum solids-residence time. Measures were instigated to control the flocculant based on the dry tph and to reduce the dosage. Excess flocculant can restrict the compaction in the paste thickener, leading to low \%m solids (Shaw \& MacNamara 2006). The underflow discharge rate was still manually set but was managed to use minor changes to maintain the target bed level. The underflow yield stress was monitored to identify improvement in thickener performance. During the 10-day initial period, the average vane yield stress was $58 \mathrm{~Pa}$ (Figure 1). The trend after optimisation (16-day operation) indicates that the yield stress averaged $77 \mathrm{~Pa}$. The yield stress increased as a result of the optimisation. However, the \%m solids decreased due to feed variations, like finer PSD.

Since the underflow yield stress is the target of paste thickeners, this PSD variation has little effect on the thickener performance. The yield stress was maintained. In actuality, the paste thickener follows the yield stress curve, producing a target yield stress (dependent on thickener design and operating conditions). The associated \%m could be read from the yield stress curve. Each sample collected has its own unique yield stress curve. Therefore, the \%m solids will vary as each sample's yield stress curve shifts back and forth along the $x$-axis $(\% \mathrm{~m})$ due to feed characteristic changes, while the thickener produces the target yield stress. The relatively steady rheology of the underflow makes the downstream stages more consistent.

\section{$3 \quad$ Tailings facility management}

Paste thickener technology entered the Indian iron market in 2015 when the Shri Bajrang Power and Ispat Ltd (SBP\&IL) plant installed a $14 \mathrm{~m}$ diameter WesTech Deep Bed ${ }^{\mathrm{TM}}$ thickener. This site provides a good study for paste thickener use to address some of the iron slimes and TSF issues. This site has a small TSF footprint. The material is stored for excavation for potential secondary use (due to high iron content), for relocation to final storage, and for water management with high rainfall.

This premier installation has a tailings production rate of about $70 \mathrm{t} / \mathrm{h}$. The tailings are placed in a $3.6 \mathrm{ha}$ TSF. The non-Newtonian underflow distribution system is pumped to one of three towers (central rises) located in the TSF. These towers define regions in the TSF to manage the filling, drying, and water collection (precipitation). The site receives just under $1.2 \mathrm{~m}$ of rain per year with $95 \%$ coming during the four months between June and September. When each tower is active the deposit spreads and the reflection of the moist surface of the fresh deposition can be seen. While one is actively receiving tailings, the other towers are in 
the drying cycle. The rainwater is collected in the far corner of the TSF. The excess water can be collected from this pool. The deposited solids have a shallow angle of repose that drains any surface water (precipitation) to the low point, allowing the material to keep drying. Figure 2 shows the several fill/dry stages as the tower is buried. The dried material could be excavated for removal.

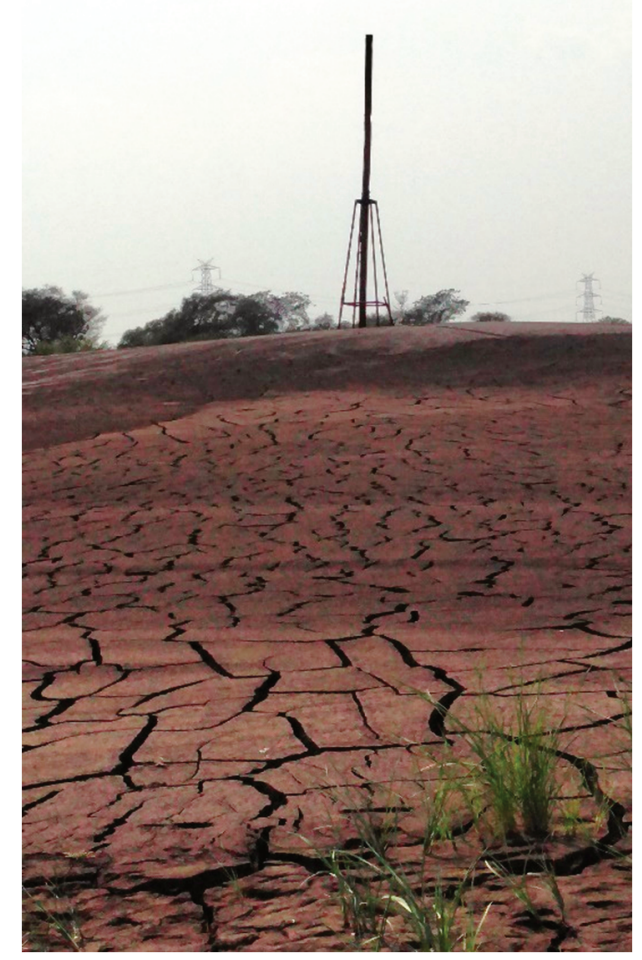

Figure 2 SBP\&IL site, one of three risers which is currently in the drying cycle

This SBP\&IL TSF management success is based on typical surface stacking methods applied to uniquely small areas. The general management plan includes the following recommendations:

- Use with small area TSF, mined out pits, or multiple excavated pits.

- Dewater with a paste thickener to a non-Newtonian underflow.

- Deposit material with a shallow angle of repose to drain water off the surface to a designated area and allow the solids to continue to dry.

- Place layers with a drying period between fill cycles.

- Excavate dried material for reuse or relocation.

Several Indian iron and steel plants have now incorporated this plan. The AMNS Debuna and Kirandul plants have installed paste thickener/surface stack systems, based on the success of SBP\&IL. These two sites installed similar $14 \mathrm{~m}$ WesTech Deep Bed units, which send the underflow to excavated drying cells. The Debuna plant production and TSF management produced a fill, dry, and excavation schedule that provides a good-handling material (Sharma et al. 2020).

The dewatering of the Kirandul slime was described as part of the optimisation study discussed earlier. The 50 to 70 Pa yield stress underflow is sent to one of two TSF sites. The Kirandul site chose to place the non-Newtonian underflow in excavated pits. Each of the pits is small, with an approximate 0.7 ha footprint. The concept was to fill a pit with a peripheral spigot placed at one end, allow it to dry while the other pit is being filled, then excavate the dried material before returning flow to the first pit. In practice, the volume 
sent to the pit ranged from about 1,000 to $2,300 \mathrm{~m}^{3} / \mathrm{d}$. This flow rate and this small pit area produced a site rise rate that can exceed $300 \mathrm{~mm} / \mathrm{d}$. This daily filling of the pit has not allowed any significant drying time between layers as the daily volume is sufficient to cover the area each day. Without a drying period, the material cannot dry to cracking prescribed for surface stacks. The initial consolidation after deposition occurred but the benefit of airdrying was not being realised. To provide additional water removal before excavating, a potential modification would be to make multiple smaller cells that could be filled to about $300 \mathrm{~mm}$, then to have no feed for at least a week. This would allow some airdrying in the hot Indian sun.

\section{Conclusion}

The rapidly growing Indian iron and steel market shows little sign of slowing down. The government is promoting the total use of the current high-grade iron ore. Fines and slimes are sintered or pelletised for steel making. The slimes tailings have high iron content and have potential for reuse. The dewatering and management of the fines and slimes can be difficult. This paper discussed a few examples of paste thickeners/surface stacks to overcome these difficulties. Several more Indian iron and steel sites are currently investigating and installing WesTech Deep Bed paste thickeners for slimes dewatering for use in low-risk storage systems. The paste thickener has shown its ability to handle the fine PSD despite wide hourly variations and to produce a steady underflow yield stress. Steady yield stress provides stable operations downstream of the thickener. Benefits of increased water recovery at the thickener, use of small TSF areas, and allowing material to be excavated on regular schedules are meeting the goal of achieving a low-risk TSF. The paste thickener/surface stack system discussed in this paper provides the growing Indian iron market with the ability to dewater and manage its slimes.

\section{References}

Indian Bureau of Mines 2020a, 'Chapter 1: executive summary', Iron \& Steel - Vision 2020, Indian Bureau of Mines, Nagpur.

Indian Bureau of Mines 2020b, 'Chapter 3: iron ore beneficiation', Iron \& Steel - Vision 2020, Indian Bureau of Mines, Nagpur.

Palmer, J 2020, 'Simulation of tailings filtration performance', in H Quelopana (ed.), Paste 2020: Proceedings of the 23rd International Conference on Paste, Thickened and Filtered Tailings, Gecamin Publications, Santiago, https://doi.org/10.36487/ACG_repo/2052_90

Sharma, A, Jha, B, Mahanta, A \& Das, A 2020, 'A case study on sustainable iron ore management using paste technology', Transactions of the Indian Academy of Engineering, vol. 5, pp. 593-601, http://doi.org/10.1007/s41403-020-00097-8

Shaw, A \& MacNamara, L, 2006, 'Design and commissioning of the Lisheen backfill plant', in R Jewell, S Lawson \& P Newman (eds), Paste 2006: Proceedings of the Ninth International Seminar on Paste and Thickened Tailings, Australian Centre for Geomechanics, Perth, pp. 347-358, https://doi.org/10.36487/ACG_repo/663_30

Vilela, V \& Salvate, M 2020, 'High pressure filters for iron ore tailings', in H Quelopana (ed.), Paste 2020: Proceedings of the 23rd International Conference on Paste, Thickened and Filtered Tailings, Gecamin Publications, Santiago, https://doi.org/ 10.36487/ACG_repo/2052_09 
